ARTICLE

\title{
Highly selective hydrogenation of arenes using nanostructured ruthenium catalysts modified with a carbon-nitrogen matrix
}

Xinjiang Cui ${ }^{1}$, Annette-Enrica Surkus ${ }^{1}$, Kathrin Junge$^{1}$, Christoph Topf ${ }^{1}$, Jörg Radnik ${ }^{1}$, Carsten Kreyenschulte ${ }^{1}$ \& Matthias Beller ${ }^{1}$

Selective hydrogenations of (hetero)arenes represent essential processes in the chemical industry, especially for the production of polymer intermediates and a multitude of fine chemicals. Herein, we describe a new type of well-dispersed Ru nanoparticles supported on a nitrogen-doped carbon material obtained from ruthenium chloride and dicyanamide in a facile and scalable method. These novel catalysts are stable and display both excellent activity and selectivity in the hydrogenation of aromatic ethers, phenols as well as other functionalized substrates to the corresponding alicyclic reaction products. Furthermore, reduction of the aromatic core is preferred over hydrogenolysis of the $\mathrm{C}-\mathrm{O}$ bond in the case of ether substrates. The selective hydrogenation of biomass-derived arenes, such as lignin building blocks, plays a pivotal role in the exploitation of novel sustainable feedstocks for chemical production and represents a notoriously difficult transformation up to now.

\footnotetext{
${ }^{1}$ Leibniz-Institute for Catalysis, University of Rostock, Albert Einstein Street, 29a, Rostock 18059, Germany. Correspondence and requests for materials should be addressed to M.B. (email: matthias.beller@catalysis.de).
} 
C atalytic hydrogenations constitute economic and clean transformations for many pharmaceutical and petrochemical processes. Due to the low price of the reductant and the $100 \%$ atom efficiency of the overall reaction, they adopt a privileged position in methodological tool box of the chemical industry. In the future, this type of transformation is expected to become even more interesting and essential because of the increasing importance of the valorization of oxygen-rich biomass. Till now, the vast majority of industrially produced chemicals depend on fossil raw materials namely petroleum, natural gas and coal. Hence, the conversion of renewable biomass to higher value-added platform chemicals currently attracts considerable attention ${ }^{1-4}$. In this respect, significant research activities are focusing on the valorization of lignin, which is one of the most abundant available feedstocks ${ }^{5,6}$. After lignin depolymerization, highly oxygenated aromatic monomers are obtained. For the consecutive utilization of such lignin-derived compounds, both heterogeneous materials and homogeneous catalysts based on $\mathrm{Pd}^{7-9}, \mathrm{Pt}^{10-12}, \mathrm{Ru}^{13-15}, \mathrm{Rh}^{16}$ and $\mathrm{Ni}^{17-29}$ have been developed which allow for reductive $\mathrm{C}-\mathrm{O}$ cleavage reactions that produce alcohols or alkene bio-building blocks (Fig. 1). Apart from this general approach, we believe it is highly desirable to develop alternative strategies based on selective arene hydrogenation to effectively utilize lignin-derived compounds and other oxygenated (hetero)arenes as feedstock for both bulk and fine chemical production.

In general, selective hydrogenation of aromatic rings plays an important role in the generation of all kinds of aliphatic derivatives, which are crucial starting materials in synthesis of polymers, resins, dyes and fine chemicals. Hence, this catalytic transformation represents also an attractive candidate for the investigation of the selective hydrogenation of lignin-derived fragments. The resulting alicyclic ethers constitute a class of very promising intermediates in the production of fine chemicals and bio-fuels ${ }^{9,30,31}$. Although hydrogenations of the arene rings of lignin building blocks are well-known, reports on the development of catalysts for the selective generation of the alicyclic ethers from such compounds are scarce ${ }^{16}$.

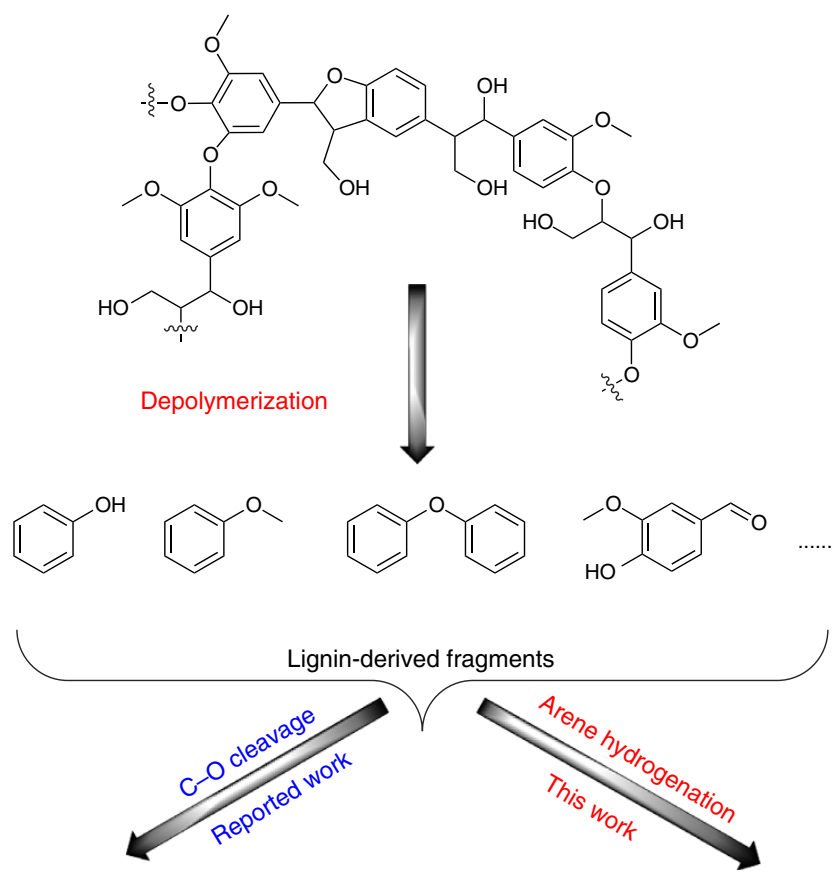

Arenes, Alcohols

Aliphatic compounds

Figure 1 | Valorization of lignin-derived building blocks. A new route demonstrated.
Nowadays, heterogeneous ruthenium nanoparticles (Ru-NPs) represent state-of-the-art catalysts for selective hydrogenation of aromatic rings which are also lower in price $\left(4,200 \$ \mathrm{ozt}^{-1}\right)$ compared with other noble metals (for example, Pd: $60,450 \$$ ozt $\left.^{-1}\right)$. By tuning shape and size of the NPs, type of supports and even by adding functionalized ligands, the performance of these materials has been greatly improved ${ }^{32-38}$. Despite all these efforts, the reported systems exhibit only low selectivity for the hydrogenation of highly reactive benzylic ethers and related derivatives. On the basis of our recent work on the development of metal NPs modified with nitrogen-doped graphene layers $(\mathrm{NGrs})^{39-46}$, we thought that such materials might allow for more selective hydrogenations. The incorporation of nitrogen atoms into a carbon matrix has been proven to affect the catalytic activity/selectivity of the resulting materials tremendously ${ }^{47,48}$. Hence, many efforts have been devoted in recent years to the development of more active $\mathrm{N}$-doped carbon materials including their usage as supports in catalysis ${ }^{49-52}$. As an instructive example in the context of lignin valorization, a $\mathrm{Pd} @ \mathrm{CN}_{0.132}$ catalyst was prepared and successfully applied in the hydrogenation of vanillin ${ }^{53}$.

Here, we describe the preparation, characterization and catalytic testing of novel ruthenium-based NP immobilized on a $N$-doped carbon support. The resulting optimal catalyst allows for unique hydrogenation of all kinds of substituted arenes including lignin-derived aromatic compounds to give the aliphatic congeners in both high activity and selectivity.

\section{Results}

Material preparation and characterization. At the start of our work, we synthesized different Ru-NPs immobilized on Vulcan powder (Ru@NDCs-X; X labels the pyrolysis temperature). To incorporate nitrogen atoms mainly three different sources (dicyanamide (DCA), cyanamide and phenanthroline) were used (Supplementary Fig. 1). The preparation of these catalysts commenced with the impregnation of Vulcan powder with an ethanolic solution of a nitrogen-ligated $\mathrm{RuCl}_{3}$ complex. The Ru@NDC nano-composites were obtained upon solvent evaporation and subsequent pyrolysis at 600,800 or $900^{\circ} \mathrm{C}$ under inert conditions. Preliminary screening of all the different catalysts revealed best results for the DCA-based materials (Table 1). Applying DCA as ligand elemental analysis of the resulting catalysts indicated that the nitrogen content dropped from 0.65 to $0.4 \mathrm{wt} \%$ as the pyrolysis temperature is increased from 600 to $900{ }^{\circ} \mathrm{C}$ (Supplementary Table 1 and Fig. 3). These findings are in agreement with the results obtained by XPS. Further evidence of $\mathrm{N}$-doping is provided by X-ray photoelectron spectroscopy (XPS). As shown in Fig. 2e and Supplementary Fig. 5, three types of nitrogen were found for the samples pyrolysed at 600,700 and $800^{\circ} \mathrm{C}$, namely: pyridinic, pyrrolic and $\mathrm{NO}_{\mathrm{x}}$ species, respectively. For the sample heat-treated at $600^{\circ} \mathrm{C}$, the amount of pyrrolic $\mathrm{N}$ was found to be only marginally higher than the pyridinic congener (49.7 versus $41.2 \%$ ), whereas in the sample pyrolysed at $700{ }^{\circ} \mathrm{C}$ the conditions moved into reverse ( 37.4 versus $55.8 \%$ ). For the $800^{\circ} \mathrm{C}$ sample, the pyrrolic $\mathrm{N}$ was found to be the dominating species again (78.0 versus $12.3 \%$ ). The quantitative analysis revealed a near-surface amount of 1.7 at $\% \mathrm{~N}$ after treatment at $600{ }^{\circ} \mathrm{C}$ and $700{ }^{\circ} \mathrm{C}$, which decreased slightly to 1.4 at $\%$ at $800^{\circ} \mathrm{C}$. To better investigate the effect of doped-nitrogen, we synthesized Ru@NDCs-800 with different nitrogen content by adjusting the amount of DCA in the synthetic process. Interestingly, decreasing the ligand amount to $100 \mathrm{mg}$, the $\mathrm{N}$ content decreased to 0.66 at $\%$, whereas no obvious change was observed for the catalyst prepared using $400 \mathrm{mg}$ of ligand (Supplementary Table 3). The amount of $\mathrm{N}$ dropped 
significantly to 0.5 at $\%$ after treatment at $900^{\circ} \mathrm{C}$. This low nitrogen content hampered the determination of the various modifications of the nitrogen. On the basis of XPS analyses, and in agreement with other NP immobilized on N-doped carbon

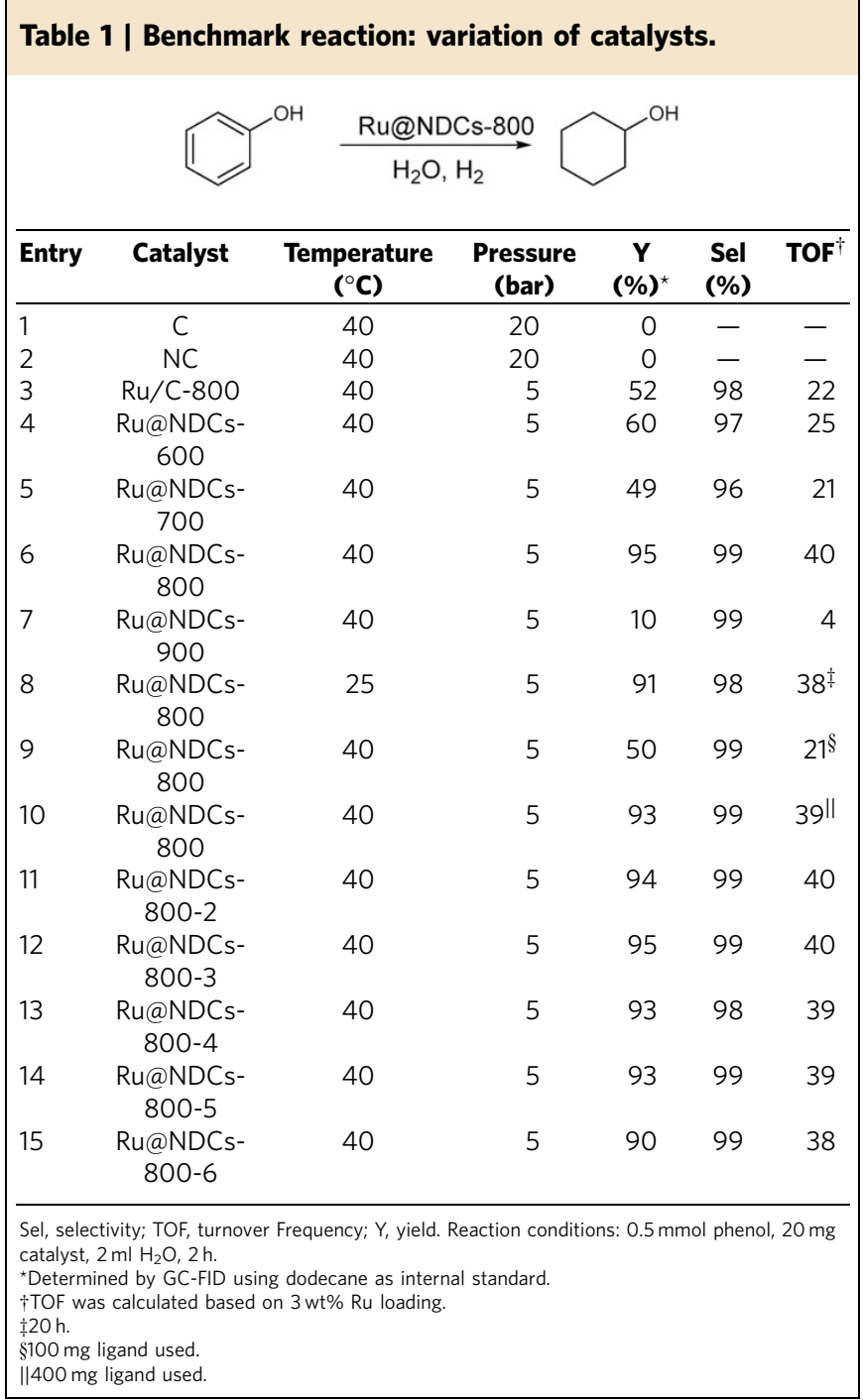

supports ${ }^{54}$, we tentatively assign the corresponding signals to pyridinic and graphitic $\mathrm{N}$, respectively. Due to the influence of the content and valence of metal-based species on the heterogeneous hydrogenation, Ru 3p XPS analyses of Ru@NDCs-catalysts were measured. These analyses suggest the formation of $\mathrm{a} \mathrm{Ru}_{2}$ phase and interaction of the active $\mathrm{Ru}$ sites with nitrogen species (Supplementary Fig. 4) ${ }^{55}$. To gain more insight into the morphology and structure of Ru@NDCs-800, high-resolution transmission electron microscopy analysis of the material was performed. The Ru-NPs are finely dispersed on the support and the average size of the NPs amount to $1.82 \pm 0.11 \mathrm{~nm}$ (Fig. 2a). On raising the pyrolysis temperature to $900^{\circ} \mathrm{C}$, the particle size of the resulting material increased to $2.5-3.0 \mathrm{~nm}$ (see Supplementary Fig. 2). However, in the absence of DCA the Ru-NPs aggregated to form larger entities ranging from 10 to $20 \mathrm{~nm}$ particles size. These results revealed that the Ru-NPs were prevented from aggregation upon decomposition of DCA and concomitant $\mathrm{N}$ incorporation into the carbon matrix during the course of the pyrolysis process. In addition, the formed $\mathrm{Ru}-\mathrm{NPs}$ might be stabilized by the pyridinic $\mathrm{N}$ and pyrrolic $\mathrm{N}$ because their lonepair electrons can serve as metal coordination sites ${ }^{56}$. Figure $2 \mathrm{~b}$ shows the images of the crystal plane of $\mathrm{Ru}$ (101), and the corresponding plane spacing was found to be $0.2 \mathrm{~nm}$. This result is in good agreement with the value obtained by X-ray diffraction (Supplementary Fig. 6). As shown from the Figs $2 \mathrm{c}$ and $2 \mathrm{~d}$, the Ru-based $\mathrm{N}$-doped carbon material develops a pronounced, well-textured morphology upon heat treatment at $800^{\circ} \mathrm{C}$.

Catalysis. After the initial screening, the performance of the prepared materials resulting from DCA was evaluated in more detail. Here, the hydrogenation of phenol to cyclohexanol with $\mathrm{H}_{2}$ pressures ranging from 5 bar to 20 bar was chosen as an industrially relevant benchmark reaction, which is of interest for bulk polyester processes ${ }^{57-59}$. We commenced our survey by control experiments with Ru-free carbon and specifically prepared the $\mathrm{N}$ doped carbon, but in neither case any product formation was observed (Table 1 , entries 1 and 2). A standard $\mathrm{Ru} / \mathrm{C}$ catalyst obtained by pyrolysis at $800^{\circ} \mathrm{C}$ in the absence of ligand (DCA) exhibited only moderate activity at 5 bar $\mathrm{H}_{2}$ and $40^{\circ} \mathrm{C}$ (Table 1 , entry 3). To our delight, the activity of the $N$-modified Ru@NDC800 catalyst is considerably increased and an almost quantitative yield of cyclohexanol is achieved at low temperature and pressure (Table 1, entry 6). In contrast, the Ru@NDCs samples originating
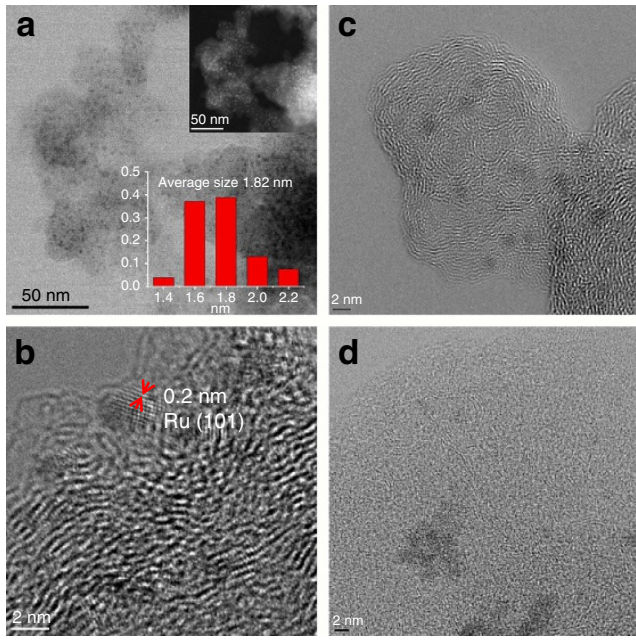

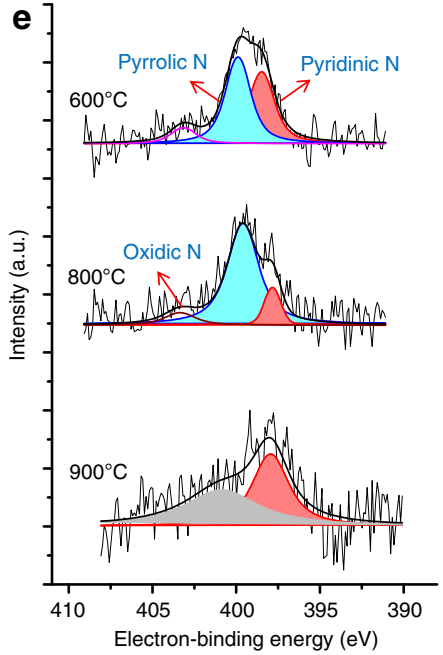

Figure 2 | High-resolution transmission electron microscopy images. Bright field HRSTEM images (a,c) and HRTEM (b) of the Ru@NDCs-800 (inset of a: HAADF image), the HRTEM image (d) of the Ru@C-800 and N1s XPS spectrum (e) of Ru@NDCs. 
from lower pyrolysis temperature featured significantly lower reactivity (Table 1 , entries 4,5 and 7 ). When the reaction was carried out for $1 \mathrm{~h}$, a significantly higher activity was also obtained in the presence of Ru@NDCs-800 (Supplementary Table 3). However, Ru@NDCs-600 or Ru@NDCs-700 might show higher TOFs based on active $\mathrm{Ru}$ atoms on the surface of the NPs.
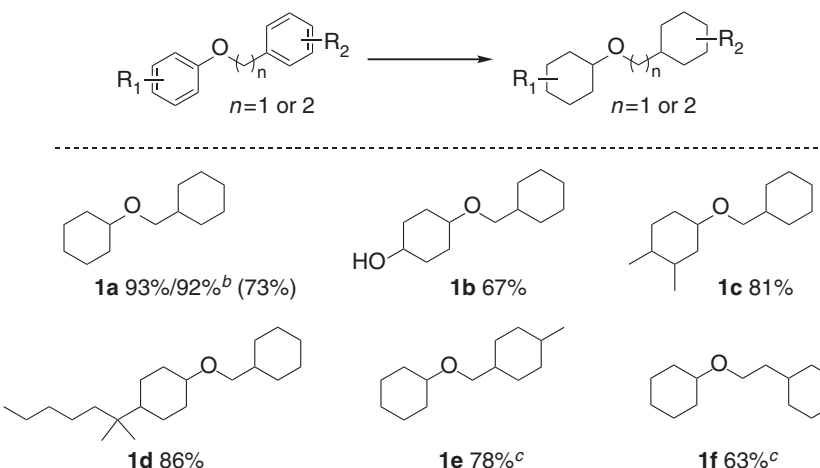

1e $78 \%{ }^{c}$

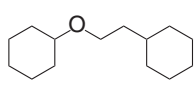

1 f $63 \%^{c}$

Figure 3 | Selective hydrogenation of benzylic ethers using Ru@NDCs-

800. Reaction conditions: $0.5 \mathrm{mmol}$ substrate, $20 \mathrm{mg}$ catalyst, $2 \mathrm{ml}$ isopropanol, $20 \mathrm{bar} \mathrm{H}_{2}, 60^{\circ} \mathrm{C}, 24 \mathrm{~h}$. Isolated yields, value in parentheses is obtained using commercial $5 \% \mathrm{Ru} / \mathrm{C} .{ }^{b} 50$ bar $\mathrm{H}_{2} .{ }^{c} \mathrm{GC}$ yield.
Moreover, the Ru@NDCs sample synthesized using low amount of ligand gave considerably lower conversion, whereas similar activity was obtained with the sample prepared in the presence of $400 \mathrm{mg}$ of ligand (Table 1, entries 9 and 10). This also demonstrates the importance of a critical amount of nitrogen.These experimental findings demonstrate the importance of nitrogen for the activity of the catalyst. Next, the reusability of the Ru@NDCs-800 nano-composite was examined since catalyst recyclability represents an integral part in the economic assessment of chemical transformations. The active material was separated from the reaction mixture via centrifugation and reused directly for five times. Gratifyingly, no obvious deactivation was detected and the yield of the desired product amounted to $93 \%$ at the sixth cycle (Table 1, entries 6 , 11-15).

Selective hydrogenation of arenes. The functional group tolerance survey of various arene substrates was conducted with the Ru@NDCs-800 catalyst. As shown in Table 2, the hydrogenation of methyl benzoate was complete at room temperature within $12 \mathrm{~h}$ (Table 2, entry 1). Furthermore, benzamide and phthalimide underwent selective reduction retaining the amide and imide groups in the substrates (Table 2, entries 2 and 3 ). In case of quinoline, which is used as a feedstock in the production of

Table 2 | Selective arene hydrogenation with Ru@NDCs-800*.

Entry Substrate

Sel, selectivity; $Y$, yield

${ }^{\star}$ Reaction conditions: $0.5 \mathrm{mmol}$ substrate, $20 \mathrm{mg}$ catalyst, $2 \mathrm{ml}$ isopropanol, 10 bar $\mathrm{H}_{2}, 60^{\circ} \mathrm{C}, 24 \mathrm{~h}$.

†Isolated yields, value in parentheses is obtained using commercial $5 \% \mathrm{Ru} / \mathrm{C}$.

$\ddagger$ Room temperature.

$\$ 80^{\circ} \mathrm{C}, 12 \mathrm{~h}$.

\|Yields detemined by ${ }^{1} \mathrm{H}$ NMR.

$\uparrow 100^{\circ} \mathrm{C}, 20 \mathrm{bar}, 12 \mathrm{~h}$. 
Table 3 | Selective hydrogenation of aromatic ethers ${ }^{\star}$.

\begin{tabular}{|c|c|c|c|}
\hline Entry & Substrate & Product & Yields $^{\dagger}$ \\
\hline 1 & & & 94 \\
\hline 2 & & & 93 \\
\hline 3 & & & 89 \\
\hline 4 & & & 88 \\
\hline 5 & & & 82 \\
\hline 6 & & & 84 \\
\hline 7 & & & 93 \\
\hline 8 & & & 88 \\
\hline 9 & & & 90 \\
\hline 10 & & & $87^{\ddagger}$ \\
\hline 11 & & & $84^{\ddagger}$ \\
\hline 12 & & & $79^{\ddagger}$ \\
\hline 13 & & & $86^{\S}$ \\
\hline 14 & & & $81^{\S}$ \\
\hline
\end{tabular}

specialty chemicals, the heterocyclic 1,2,3,4-tetrahydroquinoline is obtained in $87 \%$ yield, whereas selective hydrogenation of the pyridine ring occurred (Table 2, entry 4). Ru@NDCs-800 also exhibited good activity in the hydrogenation of methyl benzoylformate, affording a cyclohexyl-tagged tertiary alcohol in $81 \%$ yield (Table 2, entry 5). The hydrogenation of benzyl alcohol proceeded smoothly with almost quantitative formation of the corresponding saturated alicyclic alcohol. It should be noted that the yield of the latter product decreased to $75 \%$ when commercial $\mathrm{Ru} / \mathrm{C}$ was used as catalyst. This lower yield is explained by concomitant $\mathrm{C}-\mathrm{O}$ bond cleavage which leads to the formation of a considerable amount of methyl cyclohexane (Table 2, entry 6). $\mathrm{N}$-ethylcarbazole is regarded as a promising future hydrogenstorage material ${ }^{60-62}$. Hence, we tested our Ru@NDCs-800 catalyst in the hydrogenation of this peculiar heterocycle.
Interestingly, at 10 bar and $100^{\circ} \mathrm{C} \mathrm{N}$-octahydroethylcarbazole is obtained in $85 \%$ yield, demonstrating the possibility of selective partial hydrogenation. Simply by increasing the temperature to $100^{\circ} \mathrm{C}$, the fully hydrogenated perhydro-derivative was isolated in $93 \%$ yield (Table 2, entries 7 and 8 ).

Hydrogenation of benzylic compounds. In general, hydrogenolysis of benzylic compounds is observed in the course of hydrogenation processes. Especially, in benzylic ethers and alcohols the cleavage of the $\mathrm{C}-\mathrm{O}$ bond easily occurrs due to the lower $\mathrm{C}-\mathrm{O}$ bonding dissociation energy. For example, the bonding dissociation energy for benzylic ethers is $220 \mathrm{~kJ} \mathrm{~mol}^{-1}$ compared with $310 \mathrm{~kJ} \mathrm{~mol}^{-1}$ for biaryl ethers and $290 \mathrm{~kJ} \mathrm{~mol}^{-1}$ for arylethyl ethers ${ }^{27}$. Indeed, in the hydrogenation of benzyl phenyl 
Table 4 | Selective hydrogenation of biaryl ethers ${ }^{\star}$.

Entry
(n)

ether using commercial $\mathrm{Ru} / \mathrm{C}$ partial cleavage of the benzylic $\mathrm{C}-\mathrm{O}$ linkage is observed. Hence, a mixture of products including the fully hydrogenated ether, cyclohexanol and methyl cyclohexane is obtained (Fig. 3, 1a). However, applying the novel Ru@NDCs-800 catalyst gave excellent selectivity for the hydrogenation of the arene rings. As shown in Table 3, benzyl phenyl ether was smoothly converted to the corresponding alicyclic ether in $93 \%$ yield. Even at 50 bars of hydrogen no significant $\mathrm{C}-\mathrm{O}$ cleavage is observed. Similarly, substrates with pendant functional groups on the phenyl moiety such as hydroxyl, methyl and even long alkyl chains were well-tolerated and gave high yields of the corresponding cis/trans ethers (ratio 1.5-4:1; Fig. 3, 1b-1d). In addition, 1-methyl-4-(phenoxymethyl)benzene was also converted to the corresponding ether in $78 \%$ yield (Fig. 3, 1e). All these results demonstrate the specific behaviour of $\mathrm{N}$-doped ruthenium nano-composites for selective hydrogenation of aromatic rings in the presence of the benzylic $\mathrm{C}-\mathrm{O}$ bonds.

As pointed out vide supra various phenethyl ethers are easily available as platform chemicals from abundant lignin. As an example for this class of compounds the hydrogenation of phenethyl ether was investigated. Gratifyingly, the Ru@NDCs800 showed good activity for arene hydrogenation of phenethoxybenzene (Fig. 3, 1f).

Hydrogenation of aromatic ethers. To expand the scope of this arene hydrogenation, next we investigated the reactivity of various alkyl aryl ethers. Anisole, ethoxybenzene, butoxybenzene and (octyloxy)benzene were readily converted to the corresponding products in yields ranging from $88-94 \%$ (Table 3, entries 1-4). Further alkyl and methoxy substituents had no negative impact on the catalytic activity and the fully hydrogenated products were obtained as cis/trans regioisomers (3-9:1;
Table 3, entries 5-8). Arene hydrogenation of 1-methoxynaphthalene was also realized with $90 \%$ of the desired ethers formed. In addition, 2,3-dihydrobenzofuran and benzofuran were converted to the corresponding ethers in $84-87 \%$ yield. Notably, tetrahydrofurfuryl alcohol is obtained by selective hydrogenation of furfuryl alcohol, which is manufactured industrially. Moreover, the successful hydrogenation of 4-propylguaiacol and vanillin, which are both directly accessible from lignin depolymerization, was demonstrated and good yields were achieved (Table 3, entries 13 and 14). Having verified the catalytic activity of Ru@NDCs800 in the selective hydrogenation of alkyl aryl ethers, we tested the established catalytic protocol in the transformation of ligninderived biphenyl ethers.

As shown in Table 4, the conversion of a broad range of substituted biaryl ethers into the corresponding aliphatic ethers proceeded smoothly. The parent compound afforded the corresponding ether in $84 \%$ yield, whereas the hydrogenation of alkyl-substituted derivatives provided slightly higher product yields ranging from 85 to $89 \%$ (Table 4, entries 1-4).

Performing the latter reaction in the presence of commercial 5\% $\mathrm{Ru} / \mathrm{C}$, the yield for the desired product decreased to $65 \%$ due to $\mathrm{C}-\mathrm{O}$ cleavage. Finally, dibenzo-fused five- and six-membered heterocyclic substrates displayed similar reactivity and the yield of the corresponding saturated tricyclic ethers amounted to $81-91 \%$ (Table 4, entries 5-8). To investigate the high selectivity of the catalytic system, the hydrogenolysis of aliphatic ethers such as methoxycyclohexane and oxydicyclohexane were tested and no $\mathrm{C}-\mathrm{O}$ cleavage occurred. This result revealed that hydrogenation of aromatic rings is favoured compared with the cleavage of $\mathrm{C}-\mathrm{O}$ bonds. The experimental findings were also substantiated by variation of the solvent (see Supplementary Table 2), whereas higher selectivity was obtained using cyclohexane as reaction medium by virtue of its property to inhibit the hydrogenolysis reaction. 


\section{Discussion}

In summary, we developed for the first time a new type of ruthenium nano-composite immobilized on a carbon support. The described material contains finely dispersed ruthenium, which is in contact with a specific carbon-nitrogen matrix. The resulting catalysts (Ru@NDCs) are easily obtained in a practical and scalable two-step method via pyrolysis of simple ruthenium trichloride and inexpensive DCA. Combination of different analytic methods including XPS revealed the formation of graphitic nitrogen, which is identified as the functional prerequisite for the development of catalytic activity. The optimal catalyst exhibited good-to-excellent activity in the selective hydrogenation of arenes, particularly in the transformation of aromatic ethers to the corresponding alicyclic compounds with preservation of the phenyl- and benzyl C-O bonds. The utility of the catalyst opens new avenues for the valorization of ligninderived aromatic compounds to provide novel sustainable platform chemicals. In addition, industrially relevant processes such as the hydrogenation of phenol proceed under mild conditions in a green manner.

\section{Methods}

General. Unless otherwise specified, reagents and solvents were purchased from Aldrich, Fluka, Acros and Strem commercially and used as received. All compounds were characterized by ${ }^{1} \mathrm{H}$ NMR, ${ }^{13} \mathrm{C}$ NMR, GC-MS spectroscopy. ${ }^{1} \mathrm{H}$ and ${ }^{13} \mathrm{C}$ NMR spectra were recorded on Bruker Avance $300(300 \mathrm{MHz})$ or 400 $(400 \mathrm{MHz})$ NMR spectrometers. The ${ }^{1} \mathrm{H}$ and ${ }^{13} \mathrm{C}$ NMR chemical shifts are reported relative to the centre of solvent resonance $\left(\mathrm{CDCl}_{3}: 7.26(1 \mathrm{H}), 77.16(13 \mathrm{C})\right)$. EI mass spectra were recorded on an MAT 95XP spectrometer $(70 \mathrm{eV}$, Thermo Electron Corporation). For GC analysis, HP 6890 chromatograph with a $29 \mathrm{~m}$ HP5 column was used. GC-MS analysis was conducted on an Agilent GC-MS-HP5890 instrument. The products were isolated from the reaction mixture by solvent evaporation.

Typical preparation of Ru@NDCs-catalysts. $\mathrm{RuCl}_{3}(0.5 \mathrm{mmol})$ and DCA $(200 \mathrm{mg})$ were dissolved in ethanol and stirred for $2 \mathrm{~h}$ at $60^{\circ} \mathrm{C}$. Then, carbon support (VULCAN XC72R, ordered from PT (Cabot Indonesia) was added and the suspension was stirred at $60^{\circ} \mathrm{C}$ for a further period of $2 \mathrm{~h}$. After that, the mixture was cooled to room temperature and dried in vacuo at $60^{\circ} \mathrm{C}$ for $2 \mathrm{~h}$, and it was grinded to a fine powder which was subsequently pyrolyzed at $600,700,800$ or $900{ }^{\circ} \mathrm{C}$ for $2 \mathrm{~h}$ under an argon atmosphere.

\section{Catalytic hydrogenation of phenol. In a $4 \mathrm{ml}$ reaction vial equipped with a} magnetic stirring bar, phenol $(0.5 \mathrm{mmol})$ was mixed with $2 \mathrm{ml}$ IPA. Then $20 \mathrm{mg}$ of the ruthenium-based catalyst $(20 \mathrm{mg})$ was added. The reaction vials were fitted with cap and needle and then placed into a $300-\mathrm{ml}$ autoclave. The autoclave was purged thrice with $\mathrm{H}_{2}$ (10 bar), pressurized to 5 bar $\mathrm{H}_{2}$, placed into an aluminium block, heated to $40^{\circ} \mathrm{C}$ and the reaction vessels were stirred for $2 \mathrm{~h}$. After completion of the reaction, the autoclave was cooled to room temperature, $n$-dodecane was added to the reaction mixture as external standard and the mixture was diluted with ethyl acetate $(20 \mathrm{ml})$, followed by filtration and analysis of a sample by GC and GC-MS. The crude reaction mixture was concentrated in vacuo and the obtained product was analysis by NMR.

For NMR analysis of the compounds in this article, see Supplementary Methods and Supplementary Figs 7-62.

\section{References}

1. Corma, A., Iborra, S. \& Velty, A. Chemical routes for the transformation of biomass into chemicals. Chem. Rev. 107, 2411-2502 (2007).

2. Huber, G. W., Iborra, S. \& Corma, A. Synthesis of transportation fuels from biomass: chemistry, catalysts, and engineering. Chem. Rev. 106, 4044-4098 (2006).

3. Zakzeski, J., Bruijnincx, P. C. A., Jongerius, A. L. \& Weckhuysen, B. M. The catalytic valorization of lignin for the production of renewable chemicals. Chem. Rev. 110, 3552-3599 (2010).

4. Cornella, J., Zarate, C. \& Martin, R. Metal-catalyzed activation of ethers via C-O bond cleavage: a new strategy for molecular diversity. Chem. Soc. Rev. 43, 8081-8097 (2014).

5. Barta, K. \& Ford, P. C. Catalytic conversion of nonfood woody biomass solids to organic liquids. Acc. Chem. Res. 47, 1503-1512 (2014).

6. Hanson, S. K. \& Baker, R. T. Knocking on wood: base metal complexes as catalysts for selective oxidation of lignin models and extracts. Acc. Chem. Res. 48, 2037-2048 (2015)
7. Zhao, C., Kou, Y., Lemonidou, A. A., Li, X. B. \& Lercher, J. A. Highly selective catalytic conversion of phenolic bio-oil to alkanes. Angew. Chem. Int. Ed. 48, 3987-3990 (2009).

8. Zhao, C., He, J. Y., Lemonidou, A. A., Li, X. B. \& Lercher, J. A. Aqueous-phase hydrodeoxygenation of bio-derived phenols to cycloalkanes. J. Catal. 280, 8-16 (2011).

9. Li, Z., Assary, R. S., Atesin, A. C., Curtiss, L. A. \& Marks, T. J. Rapid ether and alcohol C-O bond hydrogenolysis catalyzed by tandem high-valent metal triflate plus supported Pd catalysts. J. Am. Chem. Soc. 136, 104-107 (2014).

10. Hong, D. Y., Miller, S. J., Agrawal, P. K. \& Jones, C. W. Hydrodeoxygenation and coupling of aqueous phenolics over bifunctional zeolite-supported metal catalysts. Chem. Commun. 46, 1038-1040 (2010)

11. Ohta, H., Kobayashi, H., Hara, K. \& Fukuoka, A. Hydrodeoxygenation of phenols as lignin models under acid-free conditions with carbon-supported platinum catalysts. Chem. Commun. 47, 12209-12211 (2011).

12. Zhu, X. L., Lobban, L. L., Mallinson, R. G. \& Resasco, D. E. Bifunctional transalkylation and hydrodeoxygenation of anisole over a $\mathrm{Pt} / \mathrm{HBeta}$ catalyst. J. Catal. 281, 21-29 (2011).

13. Yan, N., Yuan, Y. A., Dykeman, R., Kou, Y. A. \& Dyson, P. J. Hydrodeoxygenation of lignin-derived phenols into alkanes by using nanoparticle catalysts combined with bronsted acidic ionic liquids. Angew. Chem. Int. Ed. 49, 5549-5553 (2010).

14. $\mathrm{Xu}, \mathrm{H}$. J. et al. Ionic liquid modified montmorillonite-supported $\mathrm{Ru}$ nanoparticles: highly efficient heterogeneous catalysts for the hydrodeoxygenation of phenolic compounds to cycloalkanes. Catal. Sci. Technol. 4, 2658-2663 (2014).

15. Nichols, J. M., Bishop, L. M., Bergman, R. G. \& Ellman, J. A. Catalytic C-O bond cleavage of 2-Aryloxy-1-arylethanols and its application to the depolymerization of lignin-related polymers. J. Am. Chem. Soc. 132, 16725-16725 (2010).

16. Chatterjee, M., Ishizaka, T., Suzuki, A. \& Kawanami, H. An efficient cleavage of the aryl ether $\mathrm{C}-\mathrm{O}$ bond in supercritical carbon dioxide-water. Chem. Commun. 49, 4567-4569 (2013).

17. Zhang, J. G. et al. A series of $\mathrm{NiM}(\mathrm{M}=\mathrm{Ru}, \mathrm{Rh}$, and $\mathrm{Pd})$ bimetallic catalysts for effective lignin hydrogenolysis in water. ACS Catal. 4, 1574-1583 (2014).

18. Ferrini, P. \& Rinaldi, R. Catalytic biorefining of plant biomass to non-pyrolytic lignin bio-oil and carbohydrates through hydrogen transfer reactions. Angew. Chem. Int. Ed. 53, 8634-8639 (2014).

19. Wang, X. Y. \& Rinaldi, R. A route for lignin and bio-oil conversion: dehydroxylation of phenols into arenes by catalytic tandem reactions. Angew. Chem. Int. Ed. 52, 11499-11503 (2013).

20. Zaheer, M., Hermannsdorfer, J., Kretschmer, W. P., Motz, G. \& Kempe, R. Robust heterogeneous nickel catalysts with tailored porosity for the selective hydrogenolysis of aryl ethers. ChemCatChem 6, 91-95 (2014).

21. Samant, B. S. \& Kabalka, G. W. Hydrogenolysis-hydrogenation of aryl ethers: selectivity pattern. Chem. Commun. 48, 8658-8660 (2012).

22. Wang, X. Y. \& Rinaldi, R. Solvent effects on the hydrogenolysis of dipheny ether with raney nickel and their implications for the conversion of lignin. ChemSusChem 5, 1455-1466 (2012).

23. Wang, X. Y. \& Rinaldi, R. Exploiting H-transfer reactions with RANEY (R) Ni for upgrade of phenolic and aromatic biorefinery feeds under unusual, lowseverity conditions. Energy Environ. Sci. 5, 8244-8260 (2012)

24. Sturgeon, M. R. et al. Lignin depolymerisation by nickel supported layereddouble hydroxide catalysts. Green Chem. 16, 824-835 (2014).

25. Zhang, J. G. et al. Highly efficient, NiAu-catalyzed hydrogenolysis of lignin into phenolic chemicals. Green Chem. 16, 2432-2437 (2014).

26. Chieffi, G., Giordano, C., Antonietti, M. \& Esposito, D. FeNi nanoparticles with carbon armor as sustainable hydrogenation catalysts: towards biorefineries. J. Mater. Chem. A 2, 11591-11596 (2014).

27. He, J. Y., Zhao, C. \& Lercher, J. A. Ni-catalyzed cleavage of aryl ethers in the aqueous phase. J. Am. Chem. Soc. 134, 20768-20775 (2012).

28. Molinari, V., Giordano, C., Antonietti, M. \& Esposito, D. Titanium nitridenickel nanocomposite as heterogeneous catalyst for the hydrogenolysis of aryl ethers. J. Am. Chem. Soc. 136, 1758-1761 (2014).

29. Sergeev, A. G., Webb, J. D. \& Hartwig, J. F. A heterogeneous nickel catalyst for the hydrogenolysis of aryl ethers without arene hydrogenation. J. Am. Chem. Soc. 134, 20226-20229 (2012).

30. Schneider, H. J., Ahlhelm, A. \& Muller, W. An oxidative ether cleavage with para-nitroperbenzoic acid. Chem. Ber. Recl. 117, 3297-3302 (1984).

31. Amati, A. et al. Catalytic processes of oxidation by hydrogen peroxide in the presence of $\mathrm{Br}-2$ or $\mathrm{HBr}$. Mechanism and synthetic applications. Org. Process Res. Dev. 2, 261-269 (1998).

32. Lara, P. et al. Ruthenium nanoparticles stabilized by N-heterocyclic carbenes: ligand location and influence on reactivity. Angew. Chem. Int. Ed. 50, 12080-12084 (2011).

33. Pieters, G. et al. Regioselective and stereospecific deuteration of bioactive aza compounds by the use of ruthenium nanoparticles. Angew. Chem. Int. Ed. $\mathbf{5 3}$ 230-234 (2014). 
34. Novio, F. et al. Surface chemistry on small ruthenium nanoparticles: evidence for site selective reactions and influence of ligands. Chem. Eur. J 20, 1287-1297 (2014).

35. Machado, B. F. et al. Understanding the surface chemistry of carbon nanotubes: toward a rational design of Ru nanocatalysts. J. Catal. 309, 185-198 (2014).

36. Gutmann, T. et al. Hydrido-ruthenium cluster complexes as models for reactive surface hydrogen species of ruthenium nanoparticles. solid-state H-2 NMR and quantum chemical calculations. J. Am. Chem. Soc. 132, 11759-11767 (2010).

37. Cui, X. J., Shi, F. \& Deng, Y. Q. Ionic liquid templated preparation of $\mathrm{Ru} / \mathrm{SiO} 2$ and its activity in nitrobenzene hydrogenation. ChemCatChem. 4, 333-336 (2012).

38. Maegawa, T. et al. Efficient and practical arene hydrogenation by heterogeneous catalysts under mild conditions. Chem. Eur. J. 15, 6953-6963 (2009).

39. Jagadeesh, R. V. et al. Nanoscale Fe2O3-based catalysts for selective hydrogenation of nitroarenes to anilines. Science 342, 1073-1076 (2013).

40. Jagadeesh, R. V., Junge, H. \& Beller, M. Green synthesis of nitriles using non-noble metal oxides-based nanocatalysts. Nat. Commun. 5, 4123 (2014).

41. Westerhaus, F. A. et al. Heterogenized cobalt oxide catalysts for nitroarene reduction by pyrolysis of molecularly defined complexes. Nat. Chem. 5, 537-543 (2013).

42. Jagadeesh, R. V. et al. Selective oxidation of alcohols to esters using heterogeneous Co3O4-N@C catalysts under mild conditions. J. Am. Chem. Soc. 135, 10776-10782 (2013).

43. Stemmler, T. et al. General and selective reductive amination of carbonyl compounds using a core-shell structured Co3O4/NGr@C catalyst. Green Chem. 16, 4535-4540 (2014).

44. Stemmler, T., Surkus, A. E., Pohl, M. M., Junge, K. \& Beller, M. Iron-catalyzed synthesis of secondary amines: on the way to green reductive aminations. ChemSusChem. 7, 3012-3016 (2014).

45. Pisiewicz, S., Stemmler, T., Surkus, A. E., Junge, K. \& Beller, M. Synthesis of amines by reductive amination of aldehydes and ketones using Co3O4/NGr@C catalyst. ChemCatChem. 7, 62-64 (2015).

46. Banerjee, D. et al. Convenient and mild epoxidation of alkenes using heterogeneous cobalt oxide catalysts. Angew. Chem. Int. Ed. 53, 4359-4363 (2014).

47. Yang, S. B., Feng, X. L., Wang, X. C. \& Mullen, K. Graphene-based carbon nitride nanosheets as efficient metal-free electrocatalysts for oxygen reduction reactions. Angew. Chem. Int. Ed. 50, 5339-5343 (2011).

48. Lee, J. S., Wang, X. Q., Luo, H. M., Baker, G. A. \& Dai, S. Facile ionothermal synthesis of microporous and mesoporous carbons from task specific ionic liquids. J. Am. Chem. Soc. 131, 4596- + (2009).

49. Tan, Q., Higashibayashi, S., Karanjit, S. \& Sakurai, H. Enantioselective synthesis of a chiral nitrogen-doped buckybowl. Nat. Commun. 3, 891 (2012).

50. Yan, K. et al. Modulation-doped growth of mosaic graphene with singlecrystalline $\mathrm{p}-\mathrm{n}$ junctions for efficient photocurrent generation. Nat. Commun. 3, 1280 (2012).

51. Zhao, Y., Nakamura, R., Kamiya, K., Nakanishi, S. \& Hashimoto, K. Nitrogendoped carbon nanomaterials as non-metal electrocatalysts for water oxidation. Nat. Commun. 4, 2390 (2013).

52. Zheng, F. C., Yang, Y. \& Chen, Q. W. High lithium anodic performance of highly nitrogen-doped porous carbon prepared from a metal-organic framework. Nat. Commun. 5, 5261 (2014).

53. Xu, X. et al. Synthesis of palladium nanoparticles supported on mesoporous $\mathrm{N}$-doped carbon and their catalytic ability for biofuel upgrade. J. Am. Chem. Soc. 134, 16987-16990 (2012).
54. Jagadeesh, R. V. et al. Cobalt-based nanocatalysts for green oxidation and hydrogenation processes. Nat. Protoc. 10, 916-926 (2015).

55. Hien, N. T. B. et al. Ru-N-C hybrid nanocomposite for ammonia dehydrogenation: influence of $\mathrm{N}$-doping on catalytic activity. Materials $\mathbf{8}$, 3442-3455 (2015).

56. Lin, L., Zhu, Q. \& Xu, A. W. Noble-metal-free Fe-N/C catalyst for highly efficient oxygen reduction reaction under both alkaline and acidic conditions. $J$. Am. Chem. Soc. 136, 11027-11033 (2014).

57. Liu, H. Z., Jiang, T., Han, B. X., Liang, S. G. \& Zhou, Y. X. Selective phenol hydrogenation to cyclohexanone over a dual supported Pd-Lewis acid catalyst. Science 326, 1250-1252 (2009).

58. Duan, H. H. et al. Ultrathin rhodium nanosheets. Nat. Commun. 5, 3093 (2014)

59. Yoon, Y., Rousseau, R., Weber, R. S., Mei, D. H. \& Lercher, J. A. First-principles study of phenol hydrogenation on $\mathrm{Pt}$ and $\mathrm{Ni}$ catalysts in aqueous phase. J. Am. Chem. Soc. 136, 10287-10298 (2014).

60. Wan, C., An, Y., Xu, G. H. \& Kong, W. J. Study of catalytic hydrogenation of $\mathrm{N}$-ethylcarbazole over ruthenium catalyst. Int. J. Hydrogen Energy 37, 13092-13096 (2012).

61. Wang, Z. H., Tonks, I., Belli, J. \& Jensen, C. M. Dehydrogenation of N-ethyl perhydrocarbazole catalyzed by PCP pincer iridium complexes: evaluation of a homogenous hydrogen storage system. J. Organomet. Chem. 694, 2854-2857 (2009).

62. Eblagon, K. M. et al. Study of catalytic sites on ruthenium for hydrogenation of N-ethylcarbazole: implications of hydrogen storage via reversible catalytic hydrogenation. J. Phys. Chem. C. 114, 9720-9730 (2010).

\section{Acknowledgements}

This work was supported by the state of Mecklenburg Vorpommern. We thank Dr Carsten Kreyenschulte, Dr Jabor Rabeah and Dr Jörg Radnik for technical assistance.

\section{Author contributions}

X.C. planned and conducted the experiments, and analysed the results. C.T., K.J. and M.B. directed the project. X.C., C.T. and M.B. participated in writing the manuscript. A.-E.S. worked on the pyrolysis of the Ru catalysts. J.R. and C.K. are responsible for the XPS and TEM analysis.

\section{Additional information}

Supplementary Information accompanies this paper at http://www.nature.com/ naturecommunications

Competing financial interests: The authors declare no competing financial interests.

Reprints and permission information is available online at http://npg.nature.com/ reprintsandpermissions/

How to cite this article: Cui, X. et al. Highly selective hydrogenation of arenes using nanostructured ruthenium catalysts modified with a carbon-nitrogen matrix. Nat. Commun. 7:11326 doi: 10.1038/ncomms11326 (2016).

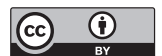

This work is licensed under a Creative Commons Attribution 4.0 International License. The images or other third party material in this article are included in the article's Creative Commons license, unless indicated otherwise in the credit line; if the material is not included under the Creative Commons license, users will need to obtain permission from the license holder to reproduce the material. To view a copy of this license, visit http://creativecommons.org/licenses/by/4.0/ 